\title{
Реформа правового регулирования рынка ценных бумаг в Европейском союзе
}

Лифииц И.М.*

Статья посвящена рассмотрению отдельных аспектов реформы правового регулирования рынка ценных бумаг в Европейском Союзе, в частности, проектов регламентов, предложенных Комиссией Европейского союза в сентябре 2009 года. После краткого обзора современной системы фондового регулирования ЕС анализируются причины, суть и нормативное обоснование законодательных предложений Комиссии по созданию Европейского совета по системным рискам (ESRB) и Европейского Агентства по ценным бумагам и рынкам (ESMA). По итогам анализа сделан ряд обобщений об основных тенденциях интеграционного правового регулирования рынка ценных бумаг, в частности, о том, что Комиссия планирует беспрецедентно глубокий уровень вторжения в полномочия национальных регуляторов рынка ценных бумаг государств-членов ЕС.

Ключевые слова: рынок ценных бумаг ЕС; европейское финансовое право; регулирование фондового рынка ЕС.

Прошлое столетие предоставило немало возможностей экономистам порассуждать о пределах вмешательства государства в регулирование экономики, а юристам - о формах и методах такого вмешательства. Взгляды были абсолютно противоположны: от «рынок все отрегулирует невидимой рукой, а там, где нужно участники рынка самоорганизуются, объединившись в ассоциации» ${ }^{1}$ до тотального контроля и уголовной ответственности за спекуляцию. Каждая страна находила свое соотношение между государственным регулированием и рынком. Финансовый кризис, похоже, смещает баланс в пользу государства, а для объединений государств - в пользу интеграционных органов.

\footnotetext{
* Лифшиц Илья Михайлович - аспирант Всероссийской академии внешней торговли, партнер Адвокатского бюро «ЭДАС». I.Lifshits@edaslawfirm.ru.

${ }^{1}$ См., например, Manning Gilbert Warren III, European Securities Regulation, Kluwer Law International, 2003, p. ${ }^{\circ} 17,29$.
} 


\section{Регулирование рынка ценных бумаг в ЕС сегодня}

Правовое регулирование рынка ценных бумаг в Европейском Союзе основано на нескольких десятках нормативных актов, принятых институтами этого интеграционного образования. Большая часть таких нормативных актов издана в виде директив Европейского парламента и Совета Европейского Союза, предполагающих имплементацию в национальное законодательство государств - членов ЕС. Среди важнейших директив в этом секторе следует упомянуть: директиву

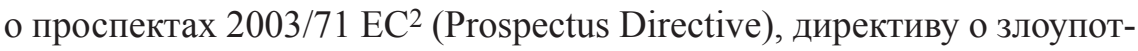
реблениях на рынке 2003/6/EC 3 (Market Abuse Directive), директиву о рынках финансовых инструментов 2004/39/EC 4 (Markets in Financial

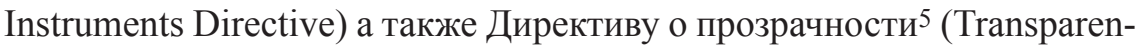
cy Directive). ${ }^{6}$ Н.Б. Шеленкова считает, что в «схему интеграционного регулирования в области рынка ценных бумаг» следует включать также и акты более общего действия, в т.ч. даже по налогообложению7. B.М. Шумилов говорит о европейском финансовом праве как об отрасли, из которой могут быть выделены подотрасли, институты и субинституты $^{8}$. Институциональная структура фондового рынка ЕС сегодня включает два комитета (Европейский Комитет по ценным бумагам European Securities Committee и Комитет Европейских Фондовых

2 Directive 2003/71/EC of the European Parliament and the of the Council of 4 November 2003 on the prospectus to be published when securities are offered to the public or admitted to trading and amending Directive 2001/34/EC, OJ 31.12.2003, L345/64.

${ }^{3}$ Directive 2003/6/EC of the European Parliament and of the Council of 28 January 2003 on insider dealing and market manipulation (market abuse) OJ 12.4.2003, L 96/16.

${ }^{4}$ Directive 2004/39/EC of the European Parliament and of the Council of 21 April 2004 on markets in financial instruments amending Council Directives 85/11/EEC and 93/6/EEC and Directive 2000/12/EC of the European Parliament and of the Council and repealing Council Directive 93/22/EEC, OJ 30.4.2004, L 145/1.

5 Directive 2004/109/EC of the European Parliament and of the Council of 15 December 2004 on the harmonization of the transparency requirements in relation to information about issuers whose securities are admitted to trading on a regulated market and amending Directive 2001/34/EC, OJ, 31.12.2004, L 390/38.

${ }^{6}$ Подробнее об этом: И.М. Лифшиц «Регулирование фондового рынка в Европейском Сообществе: образец или ориентир для международного сотрудничества» // Закон, 2009, №우, c. 242.

${ }^{7}$ Н.Б. Шеленкова. Европейское финансовое право. В 3-х томах. Том I: Правовые основы европейской интеграции. Интеграционное регулирование рынка ценных бумаг. М.: Добросвет, 2003, с. 166

${ }^{8}$ В.М. Шумилов, Международное финансовое право: учебник. - М.: Международные отношения, 2005, с. 158-159. 
Регуляторов - Committee of European Securities Regulators), имеющих консультативные функции. Функции надзора за участниками общеевропейского рынка ценных бумаг осуществляют соответствующие государственные органы государств-членов ЕС, нормативными актами лишь предусматривается сотрудничество указанных органов, обмен информацией, создание в отдельных случаях надзорных коллегий.

Идея создания единого фондового регулятора в Европейском Союзе обсуждалась с начала 90-х годов XX в. Так, еще в конце 1999 года в Плане о действиях в области финансовых услуг (Financial Services Action Plan) Комиссия отметила, что многие темы, обсуждаемые в сфере банковского, страхового и фондового регулирования проходят через все эти сферы, и, соответственно, необходимо усиленное сотрудничество для анализа опыта и выявления рисков во всех этих сферах, а в части рынка ценах бумаг, со временем, может возникнуть предложение о создании единого органа по надзору за рынком ценных бумаг 9 . «Комитет мудрецов» под председательством барона Ламфалусси, учрежденный в 2000 году для выработки предложений о реформе фондового регулирования, предположил, что единый регулятор будет нужен, если реформа фондового регулирования провалится, но выразил мнение, что для учреждения единого агентства необходимо рассмотреть изменения Договора ${ }^{10}$ (об учреждении Европейского Сообщества - далее Учредительный договор).

\section{Реформа 2009-2010}

Финансовый кризис 2007-2009 годов несколько изменил этот подход. В октябре 2008 года новому «комитету мудрецов», а именно Группе экспертов высокого уровня по финансовому надзору под председательством бывшего управляющего Международного валютного фонда Жака Ларозье, Еврокомиссией было поручено проанализировать причины кризиса и выработать адекватные меры реагирования. В феврале 2009 года был опубликован отчет этой группы ${ }^{11}$, в котором содержались предложения по введению нового регулирования сферы финансовых услуг для лучшего контроля за рисками, более координированного

${ }^{9}$ Financial Services: implementing the framework for the financial markets: Action Plan, Communication of the Commission COM (1999) 232, 11.05.1999, p. 14

${ }^{10}$ Report of the Committee of Wise Men on the Regulation of European Securities Markets, Brussels, $15^{\circ}$ February 2001; P. 41.

11 Report of High-level group of financial supervision in the EU Chaired by Jacques de Larosiere, Brussels, $25^{\circ}$ February, 2009. 
надзора и эффективного кризис-менеджмента. Проанализировав причины кризиса и способы его преодоления, Группа выработала ряд рекомендаций, воспринятых в законодательных предложениях Комиссии, опубликованных 24 сентября 2009 года и планируемых к принятию в течение 2010года.

\section{Европейский совет по системным рискам (ESRB)}

Так, Комиссия внесла проект регламента Европарламента и Совета «О макропруденциальном наблюдении за финансовой системой Сообщества и учреждении Европейского совета по системным рискам»12. Как следует из названия и пояснительного записки, в проекте предлагается учредить новый орган Сообщества (после вступления 1 декабря 2009 года в силу Лиссабонского договора - Европейского Союза), отличный от существующих структур, цель которого будет триедина: 1) развивать макропруденциальную составляющую европейского надзора для решения проблемы отрывочного (fragmented) индивидуального анализа рисков на национальном уровне; 2) усилить эффективность механизма раннего предупреждения рисков путем улучшения взаимодействия между микро- и макро-пруденциальным анализом и 3 ) обеспечить конвертацию оценки рисков в соответствующие действия уполномоченных органов ${ }^{13}$. Таким образом, новый орган относится ко всем секторам отрасли финансовых услуг, а не только к рынку ценных бумаг, однако в силу важности для системы европейского финансового регулирования его задачи и структура рассматриваются в настоящей статье.

Интересно, что для определения правового статуса нового органа Европейского Союза проектом выбрана форма регламента, подлежащего принятию Европарламентом и Советом, в отличие, например, от ныне существующих комитетов в секторе ценных бумаг (Европейского Комитета по ценным бумагам ESC - и Комитета Европейских фондовых регуляторов - CESR), статус которых определен решением Комиссии. Сделано это, видимо, по нескольким причинам: первая это повысить статус принимаемого документа, адресовать его неопределенному кругу лиц; вторая причина заключается в необходимости

12 Proposal for Regulation of the European Parliament and of the Council on Community macroprudential oversight of the financial system and establishing a European Systemic Risk Board, COM (2009) 499 final.

13 Пояснительная записка, С. ${ }^{\circ} 4$ 
возложить не только на органы европейской интеграции, но и на органы государств-членов определенные обязанности, связанные, например, с изданием ESRB актов в виде предупреждений и рекомендаций (об этом ниже). Новый орган не будет иметь прав юридического лица ${ }^{14}$.

Необходимо пояснить, что одной из причин кризиса эксперты Ларозье назвали слабость европейской системы финансового надзора, проявившейся в недостаточном внимании к выявлению рисков на макроуровне и излишнем сосредоточении на индивидуальном надзоре за отельными финансовыми компаниями ${ }^{15}$. Новый орган призван исправить эти недостатки. Для этого он наделяется полномочиями по изданию особого рода актов: предупреждений о рисках (warnings) и peкомендаций (recommendations) ${ }^{16}$. В актах первого рода констатируется наличие значительного финансового риска, в актах второго рода - указываются меры по исправлению ситуации. Эти акты не будут иметь обязательной силы ни для государств-членов, ни для национальных органов, действие предупреждений и рекомендаций будут, по замыслу Комиссии, основываться на репутации и высоком статусе членов Европейского Совета по системным рискам (ESRB), обеспечиваться «моральной властью» (moral authority). Однако адресаты актов ESRB не могут просто проигнорировать рекомендации - предполагается реакция либо путем их исполнения, либо объяснения причин неисполнения. Таким образом, применяется принцип «соответствуй или объясни» (comply or explain), достаточно часто используемый в европейском регулировании рынков ценных бумаг. Адресатами актов ESRB могут быть: Сообщество в целом, одно или несколько государств-членов, одно или несколько Европейских надзорных агентств (Европейское банковское агентство (ЕВА), Европейское агентство по страхованию и профессиональным пенсиям (ЕIOРА) и Европейское агентство по ценным бумагам и рынкам (ESMA) - о них ниже), одно или несколько национальных надзорных агентств ${ }^{17}$. Все предупреждения и рекомендации отправляются в Совет Европейского Союза и соответствующее европейское надзорное агентство для увеличения «морального давления» на адресатов ${ }^{18}$.

14 Там же, С.3.

15 Доклад Ларозье, С.11.

16 Подпункт (c) и (d) п. 2 ст. 3 Проекта.

17 Пояснительная записка, С.5; Ст. 16 и 17 Проекта.

18 Пояснительная записка, С.6. 
Ha ESRB возлагаются также задачи взаимодействовать с Системой Европейских Финансовых регуляторов (European System of Financial Supervisors - о ней ниже), с Международным Валютным Фондом и созданным по итогам антикризисной встречи «двадцатки» (G20) Советом по финансовой стабильности (Financial Stability Board).

Предложение Комиссии предусматривает, что в структуру Европейского Совета по системным рискам будут входить 3 органа: Генеральный Совет (General Board), Руководящий Комитет (Steering Committee) и Секретариат (Secretariat) ${ }^{19}$. Членами первого органа, ответственного за принятие решений, обеспечивающих выполнение возложенных на ESRB задач, являются Председатель и Вице-председатель Европейского Центрального Банка, управляющие национальных центральных банков, член Еврокомиссии, председатели трех надзорных агентств (в том числе от Европейского агентства по ценным бумагам и рынкам), а также члены без права голоса: один представитель высокого уровня от каждого государства-участника и председатель Экономического и Финансового Комитета ${ }^{20}$. В пояснительной записке к проекту разъясняется, что представители государств-членов без права голоса могут ротироваться в зависимости от обсуждаемых вопросов (относящихся к банковскому, страховому или фондовому сектору) ${ }^{21}$. Каждый член Генерального Совета имеет один голос, решения принимаются простым большинством голосов при кворуме в 2/3 от общего количества членов $^{22}$, проектом предусматривается один случай, когда решение принимается квалифицированным большинством голосов - это придание гласности предупреждения или рекомендации ESRB 23 . Повышенный порог для принятия этого решения введен в связи с тем, что опубликование акта ESRB может привести к резкому ухудшению ситуации на финансовых рынках ${ }^{24}$.

Очередные пленарные собрания Генерального Совета созываются по крайней мере четыре раза в год, а чрезвычайные собрания могут быть созваны по инициативе Председателя Генерального Совета или по запросу не менее чем одной трети членов с правами голоса ${ }^{25}$. Председатель

19 П. 1 ст. 4 Проекта.

20 П. 1 ст. 6 Проекта.

${ }^{21}$ Пояснительная записка, С. 7.

22 Ст.10 Проекта.

${ }^{23}$ Ст. 18 Проекта.

24 Пояснительная записка, С.5.

${ }^{25}$ Ст. 9 Проекта. 
и вице-председатель ESRB избираются на пятилетний срок из членов Генерального Совета, являющихся одновременно членами Общего совета (General Council) Европейского Центрального Банка ${ }^{26}$.

Второй орган ESRB - Руководящий комитет - обеспечивает процесс принятия решений Европейским Советом по системным рискам, организует текущую работу, в том числе, готовит документы, подлежащие обсуждению Генеральным Советом. Руководящий комитет состоит из Председателя и вице-председателя ESRB, пяти других членов Генерального Совета ESRB, являющихся одновременно членами Общего совета ЕЦБ, члена Европейской Комиссии, Председателей трех Европейских надзорных агентств (в том числе ESMA) и Председателя Экономического и Финансового комитета. Руководящий комитет собирается минимум раз в квартал перед собраниями Генерального Совета 27.

Проект предусматривает, что члены Генерального Совета и Руководящего Комитета выполняют свои обязанности беспристрастно и не должны получать инструкции от государств-членов 28.

Третий орган - Секретариат - выполняет аналитическую, статистическую, административную работу и осуществляет материально-техническое обеспечение деятельности ESRB. В пакет законодательных предложений Комиссии входит проект решения Совета, наделяющего Европейский Центральный Банк специальными задачами в связи с деятельностью $\mathrm{ESRB}^{29}$, поскольку именно ЕЦБ обеспечивает деятельность секретариата ESRB. Интересно, что институты Европейского Сообщества в случае принятия данного решения в первый раз применят ст. 105 (6) Учредительного Договора (ст. 126 Договора о функционировании Европейского союза в Лиссабонской редакции), которая предусматривает возможность возложить на ЕЦБ особые задачи, относящиеся к пруденциальному надзору. Учредительный Договор в Лиссабонской редакции (Договор о функционировании Европейского союза) предусматривает специальную законодательную процедуру для такого решения, а также консультацию Европарламента и ЕЦБ.

В преамбуле проекта рассматриваемого регламента в соответствии с требованиями Учредительного Договора следующим образом

26 Ст. 5 Проекта.

27 Ст. 11 Проекта.

28 РСт. 7 Проекта.

${ }^{29}$ Proposal for Council Decision entrusting European Central Bank with specific tasks concerning functioning of European Systemic Risk Board, Brussels, 23.9.2009 COM (2009) 500 final. 
обосновывается необходимость принятия мер в соответствии с принципом субсидиарности: эффективный макро-пруденциальный надзор в финансовой системе Сообщества не может быть внедрен государствами-членами в достаточной мере в силу финансовой интеграции европейских рынков. Для обоснования пропорциональности мер предложенного регламента приводится общая декларация, что последний не выходит за рамки того, что необходимо для достижения заявленных целей.

И, наконец, сердцевиной законодательных предложений Комиссии являются три проекта регламентов о создании трех Европейских надзорных агентств - European Supervisory Authorities (ESAs): Европейского банковского агентства (EBA) ${ }^{30}$, Европейского агентства по страхованию и профессиональным пенсиям (ЕIOPA) ${ }^{31}$ и Европейского агентства по ценным бумагам и рынкам (ESMA) ${ }^{32}$. Три названных агентства в тандеме с национальными финансовыми регуляторами образуют Европейскую систему финансовых регуляторов - European System of Financial Supervisors (ESFS). Они должны заменить комитеты с консультативными функциями, существующие в соответствующих секторах: Комитет европейских банковских регуляторов - Committee of European Banking Supervisors (CEBS), Комитет европейских регуляторов по страхованию и профессиональным пенсиям - Committee of European Insurance and occupational Pensions Supervisors (CEIOPS), и упомянутый выше Комитет европейских фондовых регуляторов Committee of European Securities Regulators (CESR).

Все три агентства будут иметь одинаковую внутреннюю структуру и сходные полномочия в своей сфере финансового надзора. Для развития междусекторальной кооперации будет образован объединенный комитет европейских надзорных агентств (Joint Committee of European Supervisory Authorities), который усилит «взаимопонимание, сотрудничество трех агентств, а также последовательное применение общих подходов к финансовому надзору» ${ }^{33}$. Будет также создана еди-

${ }^{30}$ Proposal for a Regulation of the European Parliament and of the Council establishing a European Banking Authority, Brussels, 23.9.2009 COM (2009) 501 final.

${ }^{31}$ Proposal for a Regulation of the European Parliament and of the Council establishing a European Insurance and occupational Pensions Authority, Brussels, 23.9.2009 COM (2009) 502 final.

32 Proposal for a Regulation of the European Parliament and of the Council establishing a European Securities and Markets Authority, Brussels, 23.9.2009 COM (2009) 503 final.

33 Пояснительная записка к каждому Регламенту, С.10. 
ная Апелляционная палата (Board of appeal), куда любое физическое или юридическое лицо, включая национального регулятора, может обратиться с жалобой на решение Агентства ${ }^{34}$. Решения Апелляционной палаты могут быть обжалованы в Суд (Трибунал) первой инстанции или Суд Европейских Сообществ, в том же порядке могут быть обжалованы решения Агентства (в случаях, когда они не обжалуется в Апелляционную палату), а также предусмотрена возможность обжалования бездействия Агентства 35.

Пояснительная записка ко всем трем регламентам содержит указание на то, что ESMA в соответствии с решением Европейского Совета будет иметь регулятивные полномочия по отношению к кредитнорейтинговым агентствам - credit rating agencies - включая регистрацию таких агентств и проведение выездных проверок. Такие полномочия предполагается включить в изменения регламента ${ }^{36}$, посвященного кредитно-рейтинговым агентствам ${ }^{37}$.

\section{Европейское агентство по ценным бумагам и рынкам (ESMA)}

Рассмотрим полномочия и структуру Европейского агентства по ценным бумагам и рынкам (ESMA), имеющего непосредственное отношение к теме настоящей статьи.

Компетенция и полномочия Европейского агентства по ценным бумагам и рынкам серьезно расширены по сравнению с компетенцией и полномочиями его правопредшественника - Комитета европейских фондовых регуляторов (CESR), имевшего сугубо консультативные функции. Сам термин «агентство» (authority) непривычен для системы финансовых органов ЕС и подчеркивает его правоприменительные и надзорные полномочия. Пояснительная записка к проекту указывает, что целями деятельности агентств финансового надзора являются улучшение функционирования внутреннего рынка, включая эффективное и последовательное регулирование и надзор, защита инвесторов, обеспечение единства и надлежащего функционирования финансовых

34 Пояснительная записка к каждому Регламенту, С.10; секция 3 каждого Проекта Регламента.

35 Глава V каждого Регламента.

36 Regulation (EC) No. 1060/2009 of 16 September 2009 of the European Parliament and of the Council on credit rating agencies, OJ, 17.11.2009 L302/1.

37 Пояснительная записка к каждому Регламенту, С. 11. 
рынков, охрана стабильности финансовой системы и укрепление международного сотрудничества надзорных органов ${ }^{38}$. Эти же цели установлены в ст. 1 проекта Регламента. К ним добавлено «обеспечение последовательного, эффективного и действенного применения права Сообщества» ${ }^{39}$.

В п. 2 ст. 1 проекта Регламента перечислены основные нормативные акты Сообщества, составляющие предмет (scope) деятельности Агентства. Текст проекта регламента не раз отсылает к перечисленным нормативным актам как к отраслевому законодательству, в частности, говоря о задаче Агентства обеспечивать последовательное применение законодательства Сообщества ${ }^{40}$; определяя, что «участник финансового рынка» - это лицо, к которому применимы требования законодательства Сообщества или соответствующего национального законодательства; определяя, что компетентные органы - это органы, определенные в законодательстве Сообщества ${ }^{41}$; говоря о праве Агентства разрабатывать технические стандарты в случаях, предусмотренных в перечисленных нормативных актах ${ }^{42}$; предоставляя Агентству право принять индивидуальное решение в отношении участника рынка в случаях, когда названное законодательство Сообщества прямо применимо к участникам рынка 43 .

Для достижения целей и задач Агентства оно наделяется полномочиями, в число которых входит (1) разработка технических стандартов, (2) издание руководящих принципов (guidelines) и рекомендаций, (3) принятие решений, (4) предоставление заключений, а также (5) осуществление исключительной надзорной компетенции в отношении организаций и деятельности, имеющих широкое распространение в Сообществе (Community-wide reach) в случаях, предусмотренных в соответствующих нормативных актах. Последнее полномочие дополнено правом проводить расследование (investigation), принудительного исполнения (enforcement) и возможностью взимать пошлины (charging fees).

Итак, первое полномочие Агентства - разрабатывать (develop) технические стандарты в сфере, предусмотренной в отраслевых

38 Там же, C.4.

39 Проекта Регламента о ESMA, п. 4 ст. 1.

40 Проект регламента о ESMA, п. 4 ст. 1.

${ }^{41}$ Проект регламента о ESMA, ст. 2.

42 Проект регламента о ESMA, п. 1 ст. 7.

43 Проект регламента о ESMA, п. 6 ст. 9 и п. 3 ст. 10. 
нормативных актах, перечисленных в регламенте (см. выше). Он предусматривает, что Агентство представляет проект технического стандарта в Комиссию, которая в течение 3 месяцев должна либо принять данный стандарт, либо проинформировать Агентство, почему стандарт не принят или не изменен. Введение данной процедуры принятия обязательных к применению стандартов, придание Агентству исключительного права «законодательной» инициативы, установление достаточно короткого срока для принятия стандартов, а также указание на Комиссию, как на единственных институт ЕС, одобряющий такие стандарты - все это стало как следствием неутешительного вывода группы Ларозье об отсутствии в Европе непротиворечивого набора норм в финансовой сфере и невозможности выработки единого решения в рамках консультативных комитетов ${ }^{44}$, так и механизмом создания единого свода правил (single rule book), призванного обеспечить единообразное применение во всем ЕC45.

Полномочие ESMA по изданию руководящих принципов (guidelines) и рекомендаций аналогично полномочию соответствующих полномочий $\mathrm{CESR}^{46}$ (там были упомянуты еще необязательные к применению стандарты, которые заменены на разработку проектов обязательных стандартов, как было рассмотрено выше). Однако в проекте 2009 года уточняется, что такого рода рекомендательные акты могут быть адресованы как компетентным органам (национальным регуляторам), так и участникам финансового рынка.

Статья 9 проекта регламента предусматривает возможность принятия ESMA обязательных к применению индивидуальных решений, адресованных участникам рынка, т.е. частным лицам. Так, предусматривается право Агентства провести расследование предполагаемого неправильного применения законодательства Сообщества. Такое расследования проводится как по запросу национальных регуляторов или Комиссии, так и по собственной инициативе Агентства. В течение двух месяцев после начала расследования Агентство направляет соответствующему рекомендацию с указанием необходимого действия, адресованную национальному регулятору, который должен исполнить ее в течение 10 рабочих дней. Если этого не происходит, Комиссия вправе

${ }^{44}$ Report of High-level group of financial supervision in the EU, op. cit, P. 27.

${ }^{45}$ Проект регламента о ESMA, преамбула, п. 14.

${ }^{46}$ Commission decision of 23 January 2009 establishing the Committee of European Securities Regulators (2009/77/EC), OJ, L 25/18 29.1.2009, Article 3. 
в течение 3 месяцев после издания рекомендации, принять решение в отношении национального регулятора, а Агентство вправе вместе с тем принять индивидуальное решение, адресованное участнику финансового рынка. Предметом такого решения может стать прекращение определенной практики, и оно отменяет любое предыдущее решение, принятое национальным регулятором по тому же вопросу. Налицо достаточно явное вмешательство в юрисдикцию национального регулятора, условием которого, как следует из проекта, являются: (1) предварительное принятие решение Комиссией, (2) необходимость в сжатые сроки исправить неподчинение национального регулятора в целях поддержания или восстановления равных условий конкуренции на рынке или обеспечения надлежащего функционирования и единства финансовой системы, (3) соответствующие нормы интеграционного законодательства, перечисленного в проекте регламента, прямо применяются к участникам рынка.

Статья 10 проекта описывает действия Агентства в случае возникновения чрезвычайной ситуации (emergency situation). Существование чрезвычайной ситуации (или чрезвычайного положения) определяется решением Комиссии, адресованного Агентству, в случаях «неблагоприятных изменений, которые могут нанести серьезный вред надлежащему функционированию и единству финансовых рынков или стабильности финансовой системы Сообщества в целом или ее отдельной части». При наличии такого решения Агентство вправе принимать индивидуальные решения, адресованные национальным регуляторам, а если они не подчиняются таким решениям, - принимать решения, адресованные непосредственно участникам рынка, если нормы законодательства Сообщества, указанные в ст. 1 (2) проекта, прямо применимы к участникам рынка (то же условие, что и в предыдущем пункте). Таким образом, ключ к улучшению регулирования финансовых рынков и в, частности рынка ценных бумаг, европейский законодатель видит в расширении надзорной компетенции органов Сообщества и предоставлении из права воздействовать на участников рынка напрямую, без посредничества национальных регуляторов.

Это право проект предоставляет Агентству и в третьем случае при наличии спора между национальными регуляторами в отношении участника рынка, поднадзорного нескольким государствам-участникам.

Очевидно, что полномочия по принятию решений и осуществлению надзорной компетенции и составляют основу, стержень реформы 
регулирования рынка ценных бумаг в Европейском союзе. Bnервые за более чем полувековую историю этого интеграционного образования его органы планируется наделить властными полномочиями по правоприменению в фондовой сфере, причем в отношении не только государств-членов или национальных регуляторов, но и в отношении профессиональных участников рынка.

В качестве отдельных задач Агентства проект (ст. 12) называет развитие надзорных коллегий (college of supervisors) в отношении финансовых конгломератов, и предоставляет Агентству право участвовать в качестве наблюдателя в таких коллегиях; названы также задачи по строительству общеевропейской надзорной культуры (ст. 14), периодической разработке отраслевых обзоров (peer review) (ст. 15), функция по координации (ст. 16) и оценке развития рынка (ст. 17), предоставления заключений институтам Сообщества (ст. 19), в рамках которых Агентство реализует свои консультативные функции, в целом аналогичные его правопредшественнику CESR.

Структура органов ESMA включает: .

(1) Совет регуляторов (Board if supervisors), .

(2) Управляющий Совет (Management Board), .

(3) Председателя (Chairperson) и .

(4) Исполнительного директора (Executive Director).

B Совет регуляторов входят: Председатель, главы национальных регуляторов, представитель Комиссии, представитель ESRB, представитель двух других Агентств по регулированию финансового рынка. Из названных категорий членов голосуют только главы национальных регуляторов. Совет регуляторов принимает заключения, в том числе консультативные, рекомендации и решения. Технические стандарты, основные положения и рекомендации и все меры, касающиеся финансовых положений, принимаются Советом квалифицированным большинством голосов по правилам определения такого большинства, предусмотренным для Совета Европейского Союза. Остальные решения принимаются простым большинством голосов.

Управляющий Совет состоит из Председателя, представителя Комиссии и 4х лиц, избранных Советом регуляторов из своих членов на срок 2.5 года. Проектом Регламента предусмотрено (ст. 32), что задача Управляющего Совета - обеспечивать выполнение миссии Агентства, а в числе полномочий, в частности названы: внесение Совету регуляторов проекта годовой и долгосрочной рабочей программы, 
выполнению бюджетных функций, принятие плана по политике в сфере управления персоналом (staff policy plan), принятие правил доступа к документам, годового отчета, назначение и освобождение от должности членов Апелляционной Палаты.

Председатель Агентства, работающий на условиях полной занятости и независимости, отвечает за подготовку материалов для работы Совета управляющих и председательствует на заседаниях этого органа, а также Управляющего Совета. Председатель назначается Советом управляющих на основе процедуры открытого отбора с согласия Европарламента на пятилетний срок. Проект Регламента (ст. 35) предусматривает право Европарламента приглашать Председателя для доклада соответствующему комитету и ответов на вопросы членов такого комитета.

И, наконец, Исполнительный директор, который, также как и Председатель, является независимым профессионалом, работающим на условиях полной занятости, отвечает за управление Агентством и за выполнение его годовой программы; он также руководит персоналом Агентства, готовит материалы для работы Управляющего Совета и «предпринимает необходимые меры, особенно в части принятия внутренних административных инструкций». Исполнительный директор назначается Советом регуляторов сроком на 5 лет.

Структура органов ESMA, закрепленная проектом Регламента, близка к структуре Европейского Центрального Банка и отражает новые властные, нормотворческие и правоприменительные функции Агентства.

В качестве правового основания, обосновывающего компетенцию Сообщества для принятия регламента об учреждении ESMA, Комиссия избрала ст. 95 Учредительного Договора 47 (после вступления в силу Лиссабонского договора - ст. 115 Договора о функционировании Европейского Союза) о сближении нормативных актов государств-членов (та же статья использовалась и для регламента об учреждении ESRB). Упреждая очевидные сомнения в компетенции органов Сообщества (с 1 декабря 2009года Союза), Комиссия и в Пояснительной записке (с. 3), и преамбуле проекта регламента (п. 10) ссылается на решение Суда Европейских Сообществ от 2 мая 2006 года по делу Великобритания против Европарламента и Совета ${ }^{48}$, в частности, на пункт44

47 Пояснительная записка, с. 3; преамбула Проекта регламента.

48 United Kingdom v. European Parliament and Council, CJCE, C-217/04. 
данного решения. В решении Суд признал, что статья 95 Учредительного договора дает надлежащие основания для учреждения «органа Сообщества, способствующего реализацию процесса гармонизации». Очевидно, что в части придания ESMA права принимать обязательные для участников рынка решения статья 95, даже в толковании упомянутого решения Суда, едва ли надлежащим образом обосновывает компетенцию Сообщества. Так, например, авторы фундаментального труда «Право ЕС» указывают на определенную ущербность универсального применения статьи 95 для регулирования внутреннего рынка, ссылаясь на дело «Германия против Парламента и Совета (C-376/98) ${ }^{49}$. Л.М. Энтин указывает, что сфера ведения Европейских Сообществ носит «строго лимитированный характер» 50

Обосновывая соответствие предложений Комиссии принципам субсидиарности и пропорциональности, Комиссия ссылается на необходимость объединить европейских регуляторов в единую сеть, а также на тот факт, что текущий надзор остается за национальными регуляторами.

По итогам анализа усилий институтов ЕС по реформе фондового регулирования, выраженных в программных документах, а также проектах нормативных актов Европейского Союза, можно сделать ряд обобщений об основных тенденциях интеграционного правового регулирования рынка ценных бумаг:

- регулирование рынка ценных бумаг все более сближается по методам, формам и институциональной структуре со смежными финансовыми секторами: банковским, и страховым регулированием;

- предоставляя создаваемому органу европейской интеграции (ESMA) право принимать индивидуальные решения, адресованные непосредственно участникам рынка и отменяющие любые решения национальных регуляторов по тому же вопросу, Комиссия беспрецедентно глубоко вторгается в полномочия национальных регуляторов рынка ценных бумаг; компетенция органов интеграции в данной сфере не является несомненной и может быть оспорена;

${ }^{49}$ EU Law, Josephine Steiner, Lorna Woods, Christian Twigg-Flesner, Oxford University Press, 2006, p. 336.

50 Европейское право. Право Европейского Союза и правовое обеспечение защиты прав человека: учебник/рук.авт.кол и отв.ред. Л.М. Энтин. -2 -е изд., пересмотр и доп. -М.: Норма, 2008, с. 48. 
- финансовый кризис 2007-2009 годов показал неэффективность механизма надзора за европейским рынком ценных бумаг, основанным только на сотрудничестве национальных фондовых регуляторов в рамках консультационного комитета и потребовал коммунитаризации ряда надзорных функций; вместе с тем основные полномочия по надзору остаются у национальных фондовых регуляторов;

- финансовый кризис обострил проблему различий законодательства государств-участников в фондовой сфере и поставил на повестку дня вопрос об унификации основных норм в данном секторе.

\section{Что дальше?}

Под влиянием угрозы, а чаще после вселенских трагедий, нациям свойственно объединяться. Лига наций появилась после первой мировой войны, ООН и Европейские Сообщества - после второй. Вот и по окончании нынешнего кризиса (или его первого этапа?) налицо новый виток интеграции.

Тридцать лет назад старший менеджер английской фондовой ассоциации Шелла Николь сказала, что рынок - как кусок мыла, если вы сжимаете его слишком крепко, он просто куда-нибудь выскользнет. ${ }^{51}$ Видимо, сегодня выскользнуть уже некуда или хватка кажется очень цепкой.

А пока директор-распорядитель Международного Валютного Фонда Доминик Стросс-Кан заявил об очевидной половинчатости реформ, обсуждаемых в Европарламенте 52 . Серьезные проблемы европейского финансового регулирования, обнажившиеся в связи с греческим кризисом, позволяют предположить, что государственное регулирование финансовых рынков только усилится.

\section{Библиографический список}

Европейское право. Право Европейского Союза и правовое обеспечение защиты прав человека: учебник / рук.авт.кол и отв.ред. Л.М. Энтин.- 2-е изд., пересмотр и доп. М.: Норма, 2008.

Шеленкова Н.Б. Европейское финансовое право. В 3-х томах. Том I: Правовые основы европейской интеграции. Интеграционное регулирование рынка ценных бумаг. М.: Добросвет, 2003.

51 Цитата по: Manning Gilbert Warren III, Op. Cit., p.31.

52 http://top.rbc.ru/economics/19/03/2010/382053.shtml 
Шумилов В.М. Международное финансовое право: учебник. М.: Международные отношения, 2005.

EU Law, Josephine Steiner, Lorna Woods, Christian Twigg-Flesner, Oxford University Press, 2006.

Manning Gilbert Warren III, European Securities Regulation, Kluwer Law International, 2003.

\section{EU Securities Regulation Reform (Summary)}

Ilya M. Lifshits*

The article is devoted to various aspects of EU securities regulation reform inter alia the legislative Proposals of the Commission of September 2009 are reviewed. After brief outlook of the today's system of securities regulation author considers reasons, nature and legal elements of the proposal to establish European Systemic Risk Board (ESRB) and European Securities and Markets Authority (ESMA). Consequently author draws several conclusions relating to the main trends of European securities markets development, particularly, that the Commission has proposed unprecedented level of interference in the powers of national securities regulators of the Member States.

Keywords: EU securities market; European financial law; EU securities regulation.

\footnotetext{
* Ilya M. Lifshits - post-graduate student of the Russian Foreign Trade Academy; Partner of EDAS Law Bureau. I.Lifshits@edaslawfirm.ru.
} 